\title{
Current perspectives of $\mathrm{SA}-4-1 \mathrm{BBL}$ in immune modulation during cancer (Review)
}

\author{
SHU-NI ZHOU ${ }^{1}$, RUI-ZHI RAN ${ }^{2}$, LI-LI TAN ${ }^{2}$ and HAO GUO ${ }^{2}$ \\ ${ }^{1}$ Department of Cardiology, The Ethnic Hospital of Enshi Tujia and Miao Autonomous Prefecture; \\ ${ }^{2}$ Department of Medical Oncology, The Central Hospital of Enshi Tujia and Miao \\ Autonomous Prefecture, Enshi, Hubei 445000, P.R. China
}

Received November 16, 2017; Accepted December 13, 2017

DOI: $10.3892 / \mathrm{etm} .2018 .5729$

\begin{abstract}
A recombinant co-stimulatory molecule capable of inducing multiple effects on varied immune cells when present in its soluble active form is termed as SA-4-1BBL. It has been reported to influence innate, adaptive, and regulatory immune cells. Recent studies confirmed its engagement with receptor, 4-1BB leading to collection of interleukin-2 (IL-2) that in turn overcomes Treg suppression. Further, a vast number of preclinical studies reported its therapeutic efficacy in the form of adjuvant subunit in cancer vaccines. Furthermore, it is also observed that it contributes significantly towards communication bridge of CD4 and NK cells. On the other hand, depletion of either NK or CD4 cells negated SA-4-1BBL's antitumor protection. The present review article is focused on the current updates of this molecule pertaining to the filed of cancer therapeutics or cancer preventives.
\end{abstract}

\section{Contents}

1. Introduction

2. 4-1BB in cancer vaccines

3. SA-4-1BBL as a potent adjuvant

4. SA-4-1BBL adjuvant effect on adaptive immunity

5. SA-4-1BBL's role in regulatory immunity

6. Conclusion

\section{Introduction}

The molecule namely 4-1BB belongs to TNFR superfamily $(1,2)$. It is a co-stimulatory molecule that is upregulated

Correspondence to: Dr Hao Guo, Department of Medical Oncology, The Central Hospital of Enshi Tujia and Miao Autonomous Prefecture, 158 Wuyang Road, Enshi, Hubei 445000, P.R. China

E-mail: guohao445000@163.com

Key words: SA-4-1BBL, immune modulation, cancer on the surface of T cells, B cells, and NK cells. The active form of the above molecule is also available on non-lymphoid cells such as dendritic cells (DCs), macrophages, neutrophils, and malignant tumor endothelial cells (3). The interaction of 4-1BB with its receptor leads to the formation of a heterotrimer with abilities to associate with TRAFS. TRAF2 initiates a signaling cascade of mitogen-activated protein (MAP) kinases and nuclear factor- $\kappa \mathrm{B}(\mathrm{NF}-\kappa \mathrm{B})$ activation, which in turn leads to the production of more TRAF1 that sustains the effect of 4-1BB stimulation. TRAF1 favors extracellular signal-regulated kinase (ERK) pathways. The end result is the expansion and survival of $\mathrm{T}$ cells leading to establishment of long-term memory (4). Key cytokines produced also include tumor necrosis factor- $\alpha$ (TNF- $\alpha$ ), interleukin-2 (IL-2), IL-12, and interferon- $\gamma(\mathrm{IFN}-\gamma)$.

The co-stimulation of 4-1BB has been reported recently to cause reduction of $\mathrm{T}$ cell exhaustion in ex vivo settings where there is persistent antigen exposure. Contrary to 4-1BB, CD28 co-stimulation in the CAR model has been shown to enhance exhaustion (5). In a transplanted melanoma model, Curran et al have shown that mice treated with anti-4-1BB antibodies generate novel forms of $\mathrm{CD}^{+}$killer and $\mathrm{CD} 8^{+}$ killer tumor infiltrating $\mathrm{T}$ cells characterized by the expression of killer-cell lectin like receptor G1 (KLRG1) and the transcription factor Eomesodermin (Eomes) independent of the T-box transcription factor (T-bet) expression. These cells were shown to produce granzymes capable of killing melanoma cells. In addition to that, amongst the members of TNFR family agonists, only 4-1BB signaling has generated the KLRG1 ${ }^{+}$Eomes $^{+}$killer phenotype, while anti-OX40, anti-GITR and anti-CD27 could not (6).

It is important here to also shed light on the regulatory aspects of 4-1BB signaling as it plays a double edged sword by generating and expanding effector immunity as well as expanding and promoting Treg functions and redirecting $\mathrm{T}$ cell polarization. In mice for example, $4-1 \mathrm{BB}$ is constitutively expressed on Tregs and can respond to $4-1 \mathrm{BBL}+\mathrm{IL}-2+$ transforming growth factor- $\beta$ (TGF- $\beta$ ) stimuli to induce their proliferation. Further, a recent study suggested that galectin- 9 controlled the duality of 4-1BB functions (7). Gal-9 binding is demonstrated to be required for the ability of 4-1BB signaling to suppress experimental autoimmune encephalomyelitis (EAE) and allergic asthma in vivo (7). In another study, 4-1BB ligand 
was shown to play a regulatory role in T cells that are weakly activated under suboptimal conditions below the threshold of 4-1BB expression and activation. Once the activation threshold was met, cell intrinsic 4-1BB was shown to downregulate the expression of 4-1BBL by endocytosis and internalization (8). This balance between the ligand and the receptor is necessary for maintaining immune system homeostasis.

\section{4-1BB in cancer vaccines}

Cancer vaccines usually consist of two major categories: Prophylactic/preventative such as Gardasil ${ }^{\circledR}$ and Cervarix ${ }^{\circledR}$ against Human Papillomavirus (HPV) 16 and 18, or therapeutic such as the dendritic cell based vaccine like Sipuleucel-T. The down side of DC vaccines is that they are relatively expensive, need to be subject customized, and are technically challenging to produce (9). Subunit vaccines consisting of tumor associated or specific antigens and immune-adjuvants, are more economically feasible and present as effective alternatives to cell-based vaccines with ease of production and marketing. The culprit in the subunit vaccines is that the immunogenicity of most antigens is low, most of them being self antigens, as well as the lack of potent and safe vaccine adjuvants capable of overcoming tumor immune evasion mechanisms. As such, in the absence of predefined tumor specific antigens and alongside conventional chemotherapy, scientists have started incorporating alternative immune modulators in clinical cancer therapies, such as the use of monoclonal antibodies targeted towards tumors and/or cells of the immune system. Some of the clinically approved candidates include i) the monoclonal antibody Herceptin (Trastuzumab) directed towards breast cancer cells expressing the human epidermal growth factor receptor 2 (Her2) protein (10). ii) Ipilimumab, an anti-CTLA antibody, which blocks the action of Tregs giving more room for Teffs and NK cells to carry out their killer functions (11). iii) Antibodies blocking the programmed death receptor-1 (PD-1) that is usually expressed by activated lymphocytes and delivers an inhibitory signal when associated with its ligand expressed by APCs as well as tumors (12). iv) Agonistic antibodies to 4-1BB costimulatory receptor, especially picked from the tumor necrosis factor superfamily due to its promising pre-clinical and clinical outcomes in fighting tumors and activating a wide array of effector immune cells.

The major drawback of anti-4-1BB antibodies is the high level of associated toxicity as reported by several studies in rodents and humans (1). Toxicity profiles are usually characterized by non-specific activation of immunity resulting in systemic inflammation, splenomegaly, lymphadenopathy, increased liver enzymes AST/ALT, as well as hepatitis. The observed toxicity is shown to be independent of $\mathrm{Fc} \gamma \mathrm{R}$ or complement system activation as inflammation was persistent in $\mathrm{Fc} \gamma \mathrm{R}^{-/-}$and complement $\mathrm{Clq}^{-/-}$or $\mathrm{C}^{-/-}$knockout mice (13). Upregulation of non-specific $\mathrm{CD}^{+}$and $\mathrm{CD}^{+} \mathrm{T}$ cells was noted upon immunizing naïve C57BL/6 mice with anti-4-1BB antibody clone $3 \mathrm{H} 3$ accompanied with high levels of IFN- $\gamma$ and TNF- $\alpha$ production. Higher doses of $3 \mathrm{H} 3$ also abrogated $\mathrm{T}$ helper cell dependent humoral immunity, caused more hepatomegaly, as well as anemia and disturbance in bone marrow's cellular compartment (14).

\section{SA-4-1BBL as a potent adjuvant}

Taking into account the various toxic facets of agonistic 4-1BB antibody treatments and the fact that naturally occurring 4-1BBL is inactive in its soluble form unless bound to a cell surface membrane. Further, streptavidin (SA) forms stable tetramers and oligomers, which is important to cluster the 4-1BB receptors on corresponding cells and enhance signal transduction. Side by side comparison studies between soluble SA-4-1BBL and 3H3 have shown SA-4-1BBL to be more potent activator than $3 \mathrm{H} 3$ while lacking the antibody associated toxicity (13).

\section{SA-4-1BBL adjuvant effect on adaptive immunity}

SA-4-1BBL has been observed to act on $\mathrm{CD}^{+}$as well as $\mathrm{CD}^{+} \mathrm{T}$ cells to fulfill its potent adjuvant role in the designed vaccine formulations. Depletion of $\mathrm{CD}^{+} \mathrm{T}$ cells 1 -day prior to tumor inoculation in two transplantable models revealed significant reduction in the therapeutic vaccine efficacy (15). Upon re-challenge of tumor free mice, long-term immunological memory was also lost in the absence SA-4-1BBL effect on $\mathrm{CD}^{+} \mathrm{T}$ cells. In another study using survivin + SA-4$1 \mathrm{BBL}$ vaccine in 3LL model, $100 \%$ of tumor eradication was achieved in a prime-boost vaccination strategy. Depletion of $\mathrm{CD}^{+} \mathrm{T}$ cells producing IFN- $\gamma 1$ day prior to vaccinations completely compromised therapeutic efficacy while depletion of NK cells had moderate yet noticeable effect on tumor growth. NK cells isolated from immunized mice showed improved killing against YAC-1 target cells in vitro (16). SA-4-1BBL adjuvant effect on innate immunity switching gears towards innate immunity, SA-4-1BBL's direct or indirect effect on NK cells has been shown to be indispensable for HPV-16 E7 recombinant protein-based therapeutic vaccine. Moreover, eradication of established tumors was mainly dependent on 4-1BB signaling (17). Activated NK cells have been shown in the literature to express 4-1BB receptor that are involved in the eradication of P815 mastocytoma in vivo although they lack the in vitro lysis function upon stimulation with anti-4-1BB monoclonal antibody, suggesting an immuno-regulatory role of NK cells in this case as compared to direct killing and effector functions (18). NK cells isolated from human peripheral blood, activated with IL-2/IL-15 cytokines for $48 \mathrm{~h}$ to upregulate $4-1 \mathrm{BB}$, and incubated with the MCF-7 human breast cancer cell line overexpressing 4-1BBL for additional $12 \mathrm{~h}$, have been shown to upregulate perforin, granzyme B, and FasL genes without enhancing cellular degranulation nor IFN- $\gamma$ production upon engagement of $4-1 \mathrm{BB}$ with $4-1 \mathrm{BBL}$ on MCF-7 cells (19).

Dendritic cells (DCs) of the innate immune system on the other hand, produce a variety of cytokines including TNF- $\alpha$ upon 4-1BB stimulation (20). SA-4-1BBL not only provides robust immune costimulatory activity in DCs in therapeutic cancer vaccines but also contributes to the delivery of TAAs conjugated through biotin to the streptavidin portion of the molecule (21). DCs in turn engulf the SA-4-1BBL-TAA conjugate and enhance antigen presentation to T cells. TC-1 or 3LL tumor-bearing mice showed significant improvement in survival upon administering SA-4-1BBL-TAA conjugate vaccine on day 6 post-tumor challenge versus administering 
SA-4-1BBL + TAA without conjugation. The therapeutic efficacy of the vaccine was associated with higher tumor infiltrating $\mathrm{CD} 8^{+} \mathrm{T}$ cells to Tregs ratio (21). Another study conducted in our lab has recently aimed at simultaneous stimulation of innate and adaptive immunity in fighting tumors using a combination of the Toll-like receptor 4 (TLR4) agonist called monophosphoryl lipid A (MPL) plus SA-4-1BBL. One vaccination with the combination of both adjuvants and HPV E7 protein as TAA resulted in $100 \%$ survival in murine TC-1 model. Vaccine formulation containing SA-4-1BBL had better efficacy $(\sim 80 \%)$ than formulation with MPL alone $(\sim 50 \%)(22)$.

\section{SA-4-1BBL's role in regulatory immunity}

SA-4-1BBL has a major impact on regulatory immunity. SA-4-1BBL drives the proliferation of activated Tregs when combined with the cytokine IL-2 while maintaining Tregs' suppressive function (23). Tregs constitutively express the IL-2 and 4-1BB receptors and SA-4-1BBL co-stimulation further upregulates the expression of both receptors. This regulatory aspect of SA-4-1BBL was shown to overcome autoimmune diseases and prevent graft rejection (23). On the other hand, we showed that SA-4-1BBL without exogenous IL-2 blocks the conversion of conventional $\mathrm{CD}^{+}{ }^{+} \mathrm{T}$ cells into induced Tregs through the production of IFN- $\gamma$ (24). One of the important mechanisms by which tumors evade suppression is the induction of iTregs in the tumor microenvironment and SA-4-1BBL has the ability to block the accumulation of iTregs even in the presence of tumor antigens and TGF- $\beta$ pressure. In the process of exploring the effects of SA-4-1BBL on Tregs, we have observed that Teffs themselves become resistant and refractory to suppression by Tregs (25), the mechanism of which is yet unknown.

\section{Conclusion}

It could be concluded from the above that 4-1BB signaling has pleiotropic effects in modulating the immune system by acting on all 3 branches: innate, adaptive and regulatory immunity. These effects are content- and model-dependent and need to be carefully considered when exploiting 4-1BB signaling for the generation of desired immune responses for therapeutic purposes.

\section{Competing interests}

The authors declare that they have no competing interests.

\section{References}

1. Mardiana S, John LB, Henderson MA, Slaney CY, von Scheidt B, Giuffrida L, Davenport AJ, Trapani JA, Neeson PJ, Loi S, et al: A multifunctional role for adjuvant anti-4-1BB therapy in augmenting antitumor response by chimeric antigen receptor T cells. Cancer Res 77: 1296-1309, 2017.

2. Tian YY, Jia CM, Li Y, Wang Y, Jiang L and Liu AC: Restoration of microRNA-373 suppresses growth of human T-cell lymphoma cells by repressing CCND1. Eur Rev Med Pharmacol Sci 20: 4435-4444, 2016.

3. Broll K, Richter G, Pauly S, Hofstaedter F and Schwarz H: CD137 expression in tumor vessel walls. High correlation with malignant tumors. Am J Clin Pathol 115: 543-549, 2001.
4. Fu ZX, Han JS, Liu F, Zhao ZL, Li DB, Shi L, Dong JT, Zhou Y and Cai JH: The study on specific umbilical blood Dc vaccine for Beige nude mice loaded human colorectal carcinoma to induce antitumor immunity. Eur Rev Med Pharmacol Sci 21: 2364-2371, 2017.

5. Long AH, Haso WM, Shern JF, Wanhainen KM, Murgai M, Ingaramo M, Smith JP, Walker AJ, Kohler ME, Venkateshwara VR, et al: 4-1BB costimulation ameliorates $\mathrm{T}$ cell exhaustion induced by tonic signaling of chimeric antigen receptors. Nat Med 21: 581-590, 2015.

6. Curran MA, Geiger TL, Montalvo W, Kim M, Reiner SL, Al-Shamkhani A, Sun JC and Allison JP: Systemic 4-1BB activation induces a novel $\mathrm{T}$ cell phenotype driven by high expression of eomesodermin. J Exp Med 210: 743-755, 2013.

7. Madireddi S, Eun SY, Lee SW, Nemčovičová I, Mehta AK, Zajonc DM, Nishi N, Niki T, Hirashima M and Croft M: Galectin-9 controls the therapeutic activity of 4-1BB-targeting antibodies. J Exp Med 211: 1433-1448, 2014.

8. Eun SY, Lee SW, Xu Y and Croft M: 4-1BB ligand signaling to T cells limits T cell activation. J Immunol 194: 134-141, 2015.

9. Hoffmann JM, Schmitt M, Ni M and Schmitt A: Next-generation dendritic cell-based vaccines for leukemia patients. Immunotherapy 9: 173-181, 2017.

10. Berretta M, Fisichella R, Borsatti E, Lleshi A, Ioffredo S, Meneguzzo N, Canzonieri V, Di Grazia A, Cannizzaro R, Tirelli U, et al: Feasibility of intraperitoneal trastuzumab treatment in a patient with peritoneal carcinomatosis from gastric cancer. Eur Rev Med Pharmacol Sci 18: 689-692, 2014.

11. Lipson EJ and Drake CG: Ipilimumab: An anti-CTLA-4 antibody for metastatic melanoma. Clin Cancer Res 17: 6958-6962, 2011.

12. Topalian SL, Hodi FS, Brahmer JR, Gettinger SN, Smith DC, McDermott DF, Powderly JD, Carvajal RD, Sosman JA, Atkins MB, et al: Safety, activity, and immune correlates of anti-PD-1 antibody in cancer. N Engl J Med 366: 2443-2454, 2012.

13. Schabowsky RH, Elpek KG, Madireddi S, Sharma RK, Yolcu ES, Bandura-Morgan L, Miller R, MacLeod KJ, Mittler RS and Shirwan H: A novel form of 4-1BBL has better immunomodulatory activity than an agonistic anti-4-1BB Ab without Ab-associated severe toxicity. Vaccine 28: 512-522, 2009.

14. Niu L, Strahotin S, Hewes B, Zhang B, Zhang Y, Archer D, Spencer T, Dillehay D, Kwon B, Chen L, et al: Cytokinemediated disruption of lymphocyte trafficking, hemopoiesis, and induction of lymphopenia, anemia, and thrombocytopenia in anti-CD137-treated mice. J Immunol 178: 4194-4213, 2007.

15. Sharma RK, Yolcu ES, Srivastava AK and Shirwan H: CD4 ${ }^{+}$ $\mathrm{T}$ cells play a critical role in the generation of primary and memory antitumor immune responses elicited by SA-4-1BBL and TAA-based vaccines in mouse tumor models. PLoS One 8: e73145, 2013

16. Srivastava AK, Sharma RK, Yolcu ES, Ulker V, MacLeod K, Dinc G and Shirwan H: Prime-boost vaccination with SA-4-1BBL costimulatory molecule and survivin eradicates lung carcinoma in $\mathrm{CD}^{+} \mathrm{T}$ and $\mathrm{NK}$ cell dependent manner. PLoS One 7: e48463, 2012.

17. Sharma RK, Srivastava AK, Yolcu ES, MacLeod KJ, Schabowsky RH, Madireddi S and Shirwan H: SA-4-1BBL as the immunomodulatory component of a HPV-16 E7 protein based vaccine shows robust therapeutic efficacy in a mouse cervical cancer model. Vaccine 28: 5794-5802, 2010.

18. Melero I, Johnston JV, Shufford WW, Mittler RS and Chen L: NK1.1 cells express 4-1BB (CDw137) costimulatory molecule and are required for tumor immunity elicited by anti-4-1BB monoclonal antibodies. Cell Immunol 190: 167-172, 1998.

19. Navabi S, Doroudchi M, Tashnizi AH and Habibagahi M: Natural killer cell functional activity after 4-1BB costimulation. Inflammation 38: 1181-1190, 2015.

20. Futagawa T, Akiba H, Kodama T, Takeda K, Hosoda Y, Yagita $H$ and Okumura K: Expression and function of 4-1BB and 4-1BB ligand on murine dendritic cells. Int Immunol 14: 275-286, 2002.

21. Sharma RK, Schabowsky RH, Srivastava AK, Elpek KG, Madireddi S, Zhao H, Zhong Z, Miller RW, Macleod KJ, Yolcu ES, et al: 4-1BB ligand as an effective multifunctional immunomodulator and antigen delivery vehicle for the development of therapeutic cancer vaccines. Cancer Res 70: 3945-3954, 2010

22. Srivastava AK, Dinc G, Sharma RK, Yolcu ES, Zhao H and Shirwan H: SA-4-1BBL and monophosphoryl lipid A constitute an efficacious combination adjuvant for cancer vaccines. Cancer Res 74: 6441-6451, 2014. 
23. Elpek KG, Yolcu ES, Franke DD, Lacelle C, Schabowsky RH and Shirwan $\mathrm{H}$ : Ex vivo expansion of $\mathrm{CD} 4^{+} \mathrm{CD} 25^{+} \mathrm{FoxP} 3^{+} \mathrm{T}$ regulatory cells based on synergy between IL-2 and 4-1BB signaling. J Immunol 179: 7295-7304, 2007.

24. Madireddi S, Schabowsky RH, Srivastava AK, Sharma RK, Yolcu ES and Shirwan H: SA-4-1BBL costimulation inhibits conversion of conventional CD4 ${ }^{+} \mathrm{T}$ cells into $\mathrm{CD} 4^{+} \mathrm{FoxP}^{+} \mathrm{T}$ regulatory cells by production of IFN- $\gamma$. PLoS One 7: e42459, 2012.
25. Sharma RK, Elpek KG, Yolcu ES, Schabowsky RH, Zhao H, Bandura-Morgan L and Shirwan H: Costimulation as a platform for the development of vaccines: A peptide-based vaccine containing a novel form of 4-1BB ligand eradicates established tumors. Cancer Res 69: 4319-4326, 2009.

(i) (9) This work is licensed under a Creative Commons CY NG NO Attribution-NonCommercial-NoDerivatives 4.0 International (CC BY-NC-ND 4.0) License. 